\title{
Leading our World Forward: An Examination of Student Leadership Development
}

\author{
Stewart G. Grunwell, MBA \\ PhD Student, Human Resources \& Management \\ DeGroote School of Business \\ McMaster University \\ Hamilton, Ontario, Canada \\ grunwesg@mcmaster.ca
}

\begin{abstract}
This study seeks to examine the processes through which leadership is fostered and developed within student leadership development programs. While there has been some scholarly literature written in this area, a dearth in the literature exists with respect to providing a detailed chronicle and examination of the complete processes employed within an exemplary student leadership development program. Through the analysis of such a program - validated by a recent NASPA (2011) study as an exemplar in the field of student leadership development such a program will be examined. Through a qualitative, grounded theory approach using interviews to inductively build a framework of understanding, seven themes of student leadership development are identified. How these findings extend existing literature is then presented, as is a new theoretical model illustrating the process through which leadership is fostered and developed within students, thereby aiding the construction of future programs.
\end{abstract}

\section{Background}

Since the 1950s, scholarly literature has supplied countless theories and definitions to further our understanding of the concept of leadership in an effort to aid and develop those in supervisory and management positions (Northhouse, 2009; NCSL, 2003). Further, such literature has provided empirical evidence illustrating the effects of leadership on both organizational and individual performance (Boerner, et al., 2007; Howell \&Avolio, 1993; Judge \& Piccolo, 2004; Piccolo \& Colquitt, 2006; Piccolo et al., 2012; Welbourne, et al., 1998). In one key study, Howell \& Avolio (1993) found the direct effects of different leadership behaviours accounted for $34 \%$ of the variance in organizational performance. These works demonstrate the importance of leadership; therefore, it follows that developing leadership is equally important, as is understanding both when and how to develop leadership effectively (Amagoh, 2009).

In an analysis of 17,000 leaders participating in Zenger/Folkman's world-wide leadership development program, it was found that, on average, those in supervisory positions had been operating without leadership training for over a decade (Zenger, 2012). As their participation in the program would suggest leadership training was needed, it follows, then, that such training was also needed the first day said individuals became supervisors. Held in concert with the findings of scholars illustrating the importance of higher education in influencing the quality of 
leadership before entering the workforce, it is argued that we, as a society, wait too long to train our leaders (Astin et al., 2000; Eich, 2008; Gardner, 1990; Osiemo, 2010; Zenger, 2012).

\section{The Importance of Developing Leadership at the Undergraduate Level}

Developing leadership in undergraduate students is one of the primary goals cited in the mission statements of universities throughout the western world (Buckner \& Williams, 1995; Zimmerman-Oster \& Burkhardt, 1999). Moreover, the development of leadership in students has become an increasingly emphasized component of the university experience, and, accordingly, nearly 1,000 recognized leadership development programs have now been implemented on college and university campuses (Eich, 2008; Riggio, et al., 2003). These programs allow students to supplement their education through providing opportunities for the application of theoretical concepts learned in their academic endeavours (Buckner \& Williams, 1995). Further, this application is critical to one's development given the relational nature of leadership - that it requires experience and cannot be taught through theory alone (Osiemo, 2010).

Defined as "a process whereby an individual influences a group of individuals to achieve a common goal" (Northouse, 2009; p. 3), leadership, as a concept, is constantly evolving as scholars routinely revise and expand its definition. Student leadership differs in that its aim is often a process-oriented, collaborative endeavour, with goals of being inclusive, empowering, purposeful, and ethical (Eich, 2008). Leadership development, then, includes each stage of growth that promotes, encourages, and assists in one's leadership education - a process which involves moving from simple to more complex dimensions of growth and learning over time (Komives et al., 2006).

In an analysis of 31 leadership programs offered at colleges and universities, Zimmerman-Oster and Burkhardt (1999) found that students who participated in leadership training programs were significantly more likely than non-participants to demonstrate long-term improvements with respect to their sense of self-understanding, ability to set goals, sense of ethics, willingness to take risks, civic responsibility, multicultural awareness, and community orientation. This illustrated the ability of higher education institutions to foster and develop the leadership abilities of its students.

Additionally, in their work, Leadership Reconsidered: Engaging Higher Education in Social Change, Astin, Astin, and associates (2000) caution that it will be difficult for students to take on leadership roles if they have not experienced effective leadership during their education. The authors place great emphasis on the development of students at the undergraduate level, stressing the importance of these institutions in guiding the next generation of leaders towards the common good while shaping the quality of their leadership (Astin et al., 2000). Similarly, Osiemo (2010) argues that if students are to take on leadership positions in their careers, they must first develop their leadership abilities concurrently with the theory learned in higher education. Held in concert with the findings of Zimmerman-Oster and Burkhardt (1999), one can see the importance of developing leadership at the undergraduate level. 


\section{The Literature on Developing Student Leadership}

While much research has been conducted regarding the effectiveness of leadership training in organizations, relatively little has been written regarding the effectiveness of leadership programs offered within institutions of higher education (Buckner \& Williams, 1995). Further, many promising student leadership programs have failed to incite significant change in their participants due to their lack of suitability to the university culture (Ruben, 2005). As such, an investigation into what constitutes an effective student leadership program, and how to develop student leaders, had been not only warranted, but long overdue.

Darin Eich (2008) conducted such a study, examining the characteristics of what he defined as high-quality leadership programs within higher education institutions. Defined as programs that have a significant positive effect on student learning and leadership development, the author developed a model of the identified requisite attributes of high-quality leadership programs based on commonalities found within four studied programs. Eich concluded that through the application of his 16 identified attributes spread across three areas of programmatic focus, leadership programs could be enhanced for improved student outcomes (Eich, 2008).

In the first of three 'clusters' of attributes, participants engaged in building a learning community, Eich establishes the value of having experienced practitioners model effective leadership behaviours during program facilitation, and the benefits of cultivating meaningful relationships and a supportive culture within the training environment (Eich, 2008). These attributes influence participant engagement through increasing trust among participants, increasing their willingness to make a genuine effort to take risks and learn from their mistakes.

The importance of small groups and experience-based learning were also highlighted, characteristics which have been found to have played a significant role in participant engagement and development through multiple studies of college and university leadership training programs (Buckner \& Williams, 1995; Eich, 2008).

In the second cluster, student-centered experiential learning experiences, Eich explains how effective programs present opportunities for participant self-reflection, both individually and collectively (Eich, 2008). Through dialogue and practical application, students learn to use presented material effectively, reflecting on their experiences and taking notes for future improvement. This coincides with the findings of Chickering and Gamson (1999), who stated that a quality program curriculum requires the ongoing practise of new skills.

Further, the role of prompt and constructive feedback in student leadership development cannot be overstated, having been found to be an essential component of quality instruction at the undergraduate level, as well as a highly desirable component of student leadership programs (Allen \& Hartman, 2009; Buckner \& Williams, 1995; Chickering \& Gamson, 1999). The quality of interpersonal relationships among participants, both with their peers and instructors, plays a role here as well - students' increased appreciation for one another's individual leadership styles and trust in one another enhances their ability to listen effectively and absorb constructive feedback to improve their leadership abilities (Eich, 2008). 
Eich's last identified cluster of high-quality program attributes declares effective programs must be both flexible to accommodate participant interests, while modeling the leadership values they present, explicitly stating their mission and values (Allen \& Hartman, 2009; Eich, 2008). An alignment of participant interest and program curriculum, then, is another mechanism of ensuring a program is successful. In addition, voluntary program registration would be ideal, unlike in organizations where leadership training is often mandated. During participant selection, then, facilitators would be wise to enlist those who are invested in both their own and others' leadership development. As an effective culture should have a respect for diverse talents and learning skills, recruiting diverse participants would also be beneficial to the success of a given program (Chickering \& Gamson, 1999). This would enable students to experience a wide variety of leadership styles while collaborating with their peers.

Lastly, through employing systems for continuous improvement, program facilitators can ensure that the information presented remains relevant, while presenting the best chances for future participant successes, through encouraging feedback from students upon completion of the program (Eich, 2008).

\section{Case Study - A Sample Student Leadership Training Program}

The works detailed in the preceding discussion provide a foundation for developing student leadership programs, using the attributes of effective programs as a guide while explaining their relevance and contributions to student leadership development. To date, however, the characteristics of effective programs have to date been identified in studies that examine leadership training across a variety of programs. Conversely, a complete account of each component of an exemplary student leadership program has to date not been chronicled for study. The present research was conducted based on the belief that such an examination will reveal new insights into the effective development of leadership in students, through accentuating the intricacies of and interrelationships between the components of such a program.

Accordingly, a detailed account of a highly successful and effective student leadership training program (facilitated at a leading university) will be considered, illustrating the methods through which the characteristics of effective leadership development are applied, the rationale for using these methods, and both the observed and self-reported effects on participants. Through understanding the reasoning behind the program's construction and what the participant outcomes have been, one will be able to form a more complete understanding of the means through which leadership is effectively fostered and developed within students.

The sample training program was initially identified as a potential example of an effective leadership development program based on the personal experience of this author and observations of its effects on other participants. However, insofar as one's opinion may be valid, more thorough criteria was developed to justify the program's suitability for study (Table 1). As would be expected, a number of the criterion listed share a resemblance to those used in existing literature. 
Table 1

Validation Criteria for Program Suitability and Effectiveness

1. The program has been proven to contribute significantly to the education and development of leadership in participants. The program's evaluation data, annual surveys, an undermentioned NASPA study, and interviews with facilitators and participants were used to validate this criterion.

2. The program has a long history of operation (36 years).

3. The program has been designed for the university student audience and tailored to the culture of the sample organization (Ruben, 2005).

4. Empirical data, as identified by Amagoh (2009) as a vital resource in identifying improvement areas in leadership development programs, was used by the organization to measure program effectiveness.

5. The program had 60 participants, representing a meaningful sample.

6. The program dedicated significant time (two weeks) to the education of participants, following the lauded "retreat" program format. (Astin et al., 2000; Buckner \& Williams, 1995; Eich, 2008)

7. Measures were employed to document both the immediate and long-term effects of the program on the participant's engagement in the material and leadership development. As discussed by Zimmerman-Oster and Burkhardt (1999), it is the long-term effects of these programs that are often most significant and, also, difficult to measure. Again, the program's evaluation data, participant surveys, and facilitator/participant interviews were used to validate this criterion.

Furthermore, a 2011 study of leadership programs initiated by the Student Affairs Administrators in Higher Education, examining the rate of successful development of leadership characteristics in student participants found the sample training program to be consistently superior to its contemporaries, with several key metrics listed in Table 2 (NASPA, 2011).

Table 2

NASPA Findings (2011)

\begin{tabular}{lll}
\hline Leadership Quality / Metric: & Sample Program & National Average \\
\hline Improvement in the leadership skills of participants: & $90.3 \%$ & $85.2 \%$ \\
Improvement in teamwork ability: & $96.8 \%$ & $83 \%$ \\
Improved understanding of group dynamics: & $93.6 \%$ & $83 \%$ \\
Improved ability to resolve conflicts: & $93.6 \%$ & $85.7 \%$ \\
Improved problem solving ability: & $96.8 \%$ & $83.5 \%$ \\
Acquired skills and abilities that will be used after & $93.6 \%$ & $79.3 \%$ \\
$\quad$ university: & & \\
\hline
\end{tabular}

Note. All metrics were based on participant reflection and were self-reported. 


\section{Methodology}

Using a qualitative, grounded theory approach, this study sought to have data generated from the respondents, as their responses to interview questions were heard, interpreted, and then developed into theory (Glaser \& Strauss, 1967). This goal was realized through a systematic examination of the data to discern any predominant patterns through the constant comparative method - by categorizing, coding, delineating categories, and connecting them (Boeije, 2002). As this research presents an emphasis on exploration, this inductive method was selected as it provides a means to examine the data until common themes are identified for the purposes of generating theory (Strauss \& Corbin, 1994).

Interviews followed McCracken's (1988) "long interview" format, as outlined in The Long Interview. Interviewees - hereafter referred to as 'respondents' - were asked biographical questions first, followed by a series of 'grand tour' questions and 'planned prompts' (McCracken, 1988). Allowing the respondents to present their own story on their own terms, the grand tour questions were open-ended in nature. To gain further information, planned prompts were utilized to elicit additional reflection or elaboration from participants. After interviews, the data was analyzed to determine the "categories, relationships, and assumptions that informed the respondent's view of the world in general and the topic in particular" (McCracken, 1988; pg. 42). Once these themes were developed, patterns, connections, and contradictions were identified.

Interviews were conducted with five (of six) program facilitators, five participants, and one observer of the training program's August 2012 session. This number of respondents achieved data saturation - the point at which further collection of information provides few further insights (Suri, 2011). Those interviewed had been through or facilitated the training program a range of two to 36 times, with the exception of the observer. Each interview followed the long interview method detailed by McCracken (1988) and lasted, on average, approximately 42 minutes. This duration was deemed suitable to cover the topic in sufficient detail without respondent fatigue becoming a factor. All interviews were tape-recorded and transcribed with the permission of the respondent. A total of 208 double-spaced pages of manuscript were derived from the interviews.

\section{Findings: Seven Interconnected Themes of Student Leadership Development}

Describing the sample training program is an interesting task, particularly because participants often suggested that explaining what they were doing and what they were learning to those outside of the program was quite difficult for them while entrenched in the training. To a degree, the exercises within the program contribute to this difficulty as many have multiple learning outcomes, some of which are evident immediately and others which don't become apparent until well after a given activity has concluded. Accordingly, an examination of the program on an exercise-by-exercise basis would prove excessive, with several repeated or similar ideas working towards broader overall goals. Therefore, these overall goals - referred to hereafter as the seven themes of the training program - will now be discussed.

Defined as overarching ideals and philosophies that resonated throughout the program and its various exercises, the identified themes were found to function as interconnected 
building-blocks, with each theme's realization necessary for the program's intended learning outcomes to occur. What follows is an account of said themes.

\section{Theme 1: A Culture of Learning and Support}

As previously identified, effective student leadership has a strong focus on collaboration and inclusivity, empowering individuals so that they feel - individually and as a collective - that they're capable of leading and supporting others (Eich, 2008). Accordingly, the sample training program focuses, to a considerable degree, on building a supportive culture within the learning environment. Through a variety of exercises and activities, the program seeks to create a genuine connection between participants, developing trust between one another, within the group as a whole, and between participants and facilitators. Through an initial focus on inclusion and effective communication, participants are swiftly introduced to one another and, soon after, are naturally beginning to lean on their peers for support and understanding in an alarmingly brief amount of time. As one respondent explained, "people are pushed so far, to their limits, through emotional barriers that they find support in each other. Because they're going through the same thing." Through understanding shared experiences, participants are naturally drawn to one another for support, which initiates the process of building connections within the group.

As established in the literature, developing meaningful connections amongst all involved in the program and establishing a climate of trust enhances trainee engagement and retention of information within student leadership programs (Eich, 2008). A trust in the program is cultivated through experienced participants (approximately 35 percent of the program participants are not experiencing the training for the first time) as well as the training facilitators. Through modelling the effective use of the material presented throughout the program, participants can witness the usefulness of the skills being presented, increasing their trust in the material and in the exercises. As explained by a respondent,

"We look to [experienced participants] to teach a lot of the skills [new participants] need to learn, often times it doesn't come from us (facilitators)...It might come from a late night conversation they've had with a returning [participant], and, sometimes, that's more valuable than [a facilitator presenting the material]. Teaching by experience, teaching by example is often more beneficial for this group."

Through the use of examples, the experienced leaders are able to provide encouragement to their peers, sharing stories of their struggles while learning the material. Through demonstrating a proficiency with the skills taught in training, experienced participants are able to provide evidence of how those struggles can be overcome, while fostering their own leadership abilities concurrently. These behaviours echo the findings of Komives and colleagues (2006), who wrote of the importance of effective role modeling behaviours in developing student leadership.

Further demonstrating the significance of the role experienced leaders serve in cultivating a supportive environment within the training program, another respondent explained "as a returner, as a second-timer, your job isn't really to learn the information - it's to support those 
who are learning it for the first time...that's what happens, because you've had exposure to it." Regarding the facilitators' role in providing support to trainees, another respondent added,

"There's a lot of time spent by the people running the training watching what [participants] are doing. Watching who's struggling, who needs a conversation to help them through something, so that...if things aren't going well, someone's not getting the content, we [are able to help them work towards understanding the content]."

Alluded to as a "network of support" by one respondent, as soon as this environment is established, facilitators begin efforts to empower their leaders-in-training, creating a complete learning environment. To that end, a philosophy known as the "growing edge" is introduced, which suggests that participants strive to challenge themselves to face new experiences, some of which - because these skills or experiences are not a part of that individual's 'sphere' of existence - will feel new, different, or uncomfortable. As one respondent explained:

"I didn't invent growing edge, but I love it. I love to introduce it early, because of what it does...it normalizes being anxious and feeling awkward in a training situation. It normalizes that, yes, of course you're going to feel awkward - this isn't a part of you. Yes, of course you're going to be anxious and fearful, [however]...this is the time where we're going to make mistakes, so we'll make less mistakes later. It's okay to make a mistake here. There's nothing wrong with that at all. What's wrong is not taking the risk and not trying to get better."

Through the safety of the support from their peers and training facilitators, combined with the encouragement to practise their skills, to take risks - the notion that mistakes are welcomed, and even encouraged, as long as they're used as a learning experience - the program works to foster a culture that encourages leadership development where participants make a genuine effort to take chances and engage in the material, a crucial element of student leadership development, as scholars have noted (Eich, 2008; Komives et al., 2006).

\section{Theme 2: The Importance of Practise and Practical Application}

"Practise with feedback. That's how they get better."

A simple notion, but one that is inherent throughout the sample training program. Working as the next step in the development of student leaders, the benefits of practising the new skills presented in leadership training - the enhancement of one's leadership ability - are augmented by a supportive culture with meaningful connections among participants, as previously discussed. Through practising within a nurturing environment, feedback is more likely to be absorbed and retained, as a mutual respect, trust, and understanding exists between participants and their peers as well as with program facilitators (Eich, 2008).

Constructive feedback following practical application exercises allows participants to reflect upon their performance, understanding their strengths and weaknesses, and is a crucial component of student development at the undergraduate level (Buckner \& Williams, 1995; Chickering \& Gamson, 1999). Given the opportunity to continue to practise after receiving 
feedback - repeating a cycle of practise, receive feedback, reflect, and practise again participants are able to increase their proficiency with the content over time. In concert with the observations and, when necessary, intervention of facilitators, practical application allows for the content to, as one respondent explained, "become ingrained, [to] become a natural part of the way [one] interacts with people." The culture of the learning environment plays a role here as well, as experienced leaders can role model this sentiment, demonstrating to new trainees that, while such practise may feel awkward or uncomfortable initially, they have been able to hone these skills with said practise and make them a part of who they are as a leader.

Practical experience gained throughout the program was also found by respondents to be vital in establishing confidence in one's ability as a leader. As one respondent explained,

"The program...is geared towards setting people up to do as good of a job as they can on their own. So that it's less 'come and ask us what to do, and we'll tell you what to do,' it's more, 'we'll give you the tools and the skills to come up with best judgement.",

Respondents found that building the confidence of participants through simulations aided their ability to take initiative and adapt in high-pressure situations, adjusting to difficult circumstances to solve problems, skills which are necessary to succeed in a leadership role.

"They expose [participants] to uncomfortable things, because they know that uncomfortable happens. And they want to make them okay with that...they want [participants] to be able to - at the end of that training - walk into the room and 'be the [leader].' ...they also want to develop the student leaders...to make them more confident and [adaptable], to make them more effective communicators...developing their emotional maturity, their emotional intelligence, their ability to think critically, their ability to collaborate with other people, and to know what tools to use at what times."

\section{Theme 3: Reflection and Self-Directed Learning}

As Eich (2008) found, effective student leadership development programs present opportunities for participant self-reflection. Practise, as referenced earlier, certainly provides one avenue for such reflection, presenting participants with opportunities for self-assessment of their abilities. Providing further opportunity for reflection throughout the training program, numerous activities are presented wherein the purpose and outcome(s) aren't entirely - if at all transparent to participants. As one respondent exclaimed, there are some activities where, "at face value, why the hell do we do that?!" And, while each exercise has its own specific, intentional purpose(s), the consistent message from respondents with respect to these activities was that their goal is to have participants thinking, reflecting, and learning through an experiential process, which, as the literature indicates, increases the absorption of content for undergraduate students in leadership programs (Buckner \& Williams, 1995; Chickering \& Gamson, 1999; Komives et al., 2006). Moreover, there are additional activities run wherein if the desired outcomes were known to participants, they would not be achieved.

"It's about... pushing people in a way that they're not used to being pushed. So then [participants are] growing together and bonding... if they told [participants], 'okay, we're 
going to do something that will challenge you and make some of you uncomfortable because we want you to grow from it.' I don't think it would have the effect they (the training facilitators) would want."

For these exercises to be successful, a climate of trust must be established within the culture of the learning environment, as detailed previously. With participants trusting the program, facilitators, and their peers, a strong buy-in can be achieved, giving facilitators greater license to run activities with vague or unknown purposes - exercises that allow for self-directed learning and deeper reflection.

"Going through [the training program]...I felt like everything we did had a reason, and if it wasn't provided then, it was provided later...I think, part of that - not explaining everything - is so that when you have those 'ah hah' moments...it's more meaningful, rather than [the facilitators] putting it into a [given] context...everyone learns differently, and everyone uses the [content] differently, so [the facilitators] can't necessarily say 'we're doing this for this reason,' because... everyone takes away something different. ...you're learning about yourself [and] your leadership style."

Lastly, experienced leaders can assist in demonstrating their commitment to the program, providing the needed legitimacy behind such exercises. Through providing support and encouragement, they can communicate an understanding of the uncomfortable feelings towards such exercises, while echoing the sentiment of the 'growing edge' ideology of taking risks - and possibly making mistakes in the process - while learning and growing from the experience.

\section{Theme 4: Immersion in the Program}

Unanimously heralded by respondents as a crucial piece of developing the supportive culture within the training program, the 'retreat' format of the sample training program - having every participant live together in a small, isolated community for the first week of training - was viewed as one of the program's greatest strengths. "I think the most effective thing they (the facilitators) do is they make us live in the same [area] together," a respondent explained. In further discussing the benefits of the 'live-in' training environment - specific to what happens after the formal training concludes each day - other respondents stated:

“...you're experiencing training 24 hours a day...you can't get away from it...it's great for team development...it's [beneficial for participants] because they'll find people to connect with...[and] support them through whatever they're going through."

“... [Participants living] together...really forces bonding extremely quickly. Paired with the intensity of the training, they use each other to debrief in their own time."

Further developing this sense of immersion within the program, participants are encouraged to leave their technology at home - cell phones, computers, etc. - and to inform family and friends that they'll be virtually unavailable during their time in training. "[Separation] from the outside world...makes the program a culture within itself," explained a respondent. 
As noted by scholars, the 'retreat' program format has been a popular practice in student leadership development programs for some time (Buckner \& Williams, 1995). However, where the sample training program differs from many comparable programs is that it is held on-site, within the community where the student leaders will work throughout the year - lending a sense of realism to the material, subtly indicating that the training is suitable to university culture, an important factor in engaging undergraduate students in training (Ruben, 2005). As a respondent explained, "...a lot of institutions take people to some kind of remote camp to make [training] happen. We're able to do that [on-site], and I think that's a really important piece of how they learn [and] develop as a team."

\section{Theme 5: Group Process}

Noticeably more unique to the sample training program - compared with the literature as well as respondent experiences - is the program's focus on group process. While to a degree this focus is in place to contribute to a successful training environment, this focus is also attributed to the intended outcomes of the sample program, one of which is to develop supportive and highly functional teams of leaders that work as part of a greater leadership system concurrently. At times, each leader will have to work with a level of autonomy, and, as such, developing one's own leadership abilities is an important aspect of the program. And yet, there are other scenarios wherein the leadership group must work together, and so the training looks to develop each participant's ability to function within the group.

Relating to the theme of reflection, one respondent explained that participants are challenged to reflect upon the notion of "how much influence am I going to have on this group, and how much influence will I let this group have over me, or, does this group expect to have over me?" In doing so, such exercises challenge leaders to become more conscious of the thoughts and views of others, a notion that "being a [leader] requires you to be able to set aside your personal opinion at times and be open to the opinions of others and facilitate more than participate." In doing so, the program seeks to achieve a 'reality-check' of sorts, balancing out the confidence in oneself that can come from the empowering, supportive nature of the training environment. This focus also prepares participants for the professional environment beyond the university/student context, to function as members of working teams in society, one of the primary purposes of student leadership training (Astin et al., 2000).

\section{Theme 6: Flexibility vs. Consistency}

Within the literature, considerable emphasis is placed upon the notion of flexibility in training programs to accommodate students' interests and abilities, grounded in the program's mission and values (Allen \& Hartman, 2009; Eich, 2008). Within the sample training program, a similar paradigm exists, though the degree to which the program is successful in balancing the competing demands of flexibility to meet individual needs and consistency in presenting its content (to achieve its mission) varies from person to person, as described within the following respondent quotations:

"We have some control over the design, but...what do we do when things happen? Teachable moments [arise] and we have to respond." 
"We see success in the results that we get from our [student leaders], so we typically don't change a whole lot from [the training] process... sometimes we do need to get a little more innovative...the changes [we do make relate to] additions or subtractions to make the learning experience more enjoyable or applicable to the changing trends."

From the responses, it is evident that participants within the program place great importance on the ability of leadership development programs to be flexible in their design to accommodate participant needs, to support them through difficulties and ensure they're digesting the content while immersed in the training - an area in which respondents found the program to be successful. In accordance with past research, respondents have expressed a desire to see training practices evaluated, and improvement systems employed in a proactive effort to ensure future participant successes (Eich, 2008).

Regardless of the degree of past success, it is important to note that effective student leadership programs should be mindful to remain relevant to current leadership needs and trends while maintaining flexibility in program execution to meet the needs of participants.

\section{Theme 7: Ongoing Development}

Throughout the interview process, respondents continued to express the idea of leadership development as an ongoing process - one that doesn't end at the conclusion of the training program. As noted by one respondent,

"Part of making it a leadership program is the follow-up to it. You don't just give a two week session to somebody and say, 'okay, now you're a leader...' Being a leader is about moving forward... a stagnant leader isn't a leader anymore.”

Within the studied organization, systems have been put into place to provide continuous learning and development in this regard. Whether through weekly meetings or monthly training sessions, the program aims to provide development in areas identified by examining the current environment - analyzing current trends and through making observations with respect to developmental needs within the leadership group. Though the results of these initiatives appear to be mixed among respondents - many expressing the sentiment that the initial two-week training program is far more effective, mainly due to the 'retreat' aspect that allows complete immersion in the learning environment - it was also determined that the intent behind such initiatives was appreciated. Providing opportunities for leaders to continue to develop was seen as a resoundingly important concept among respondents, one that should resonate through the culture of such an organization, themes echoed in the literature (Chickering \& Gamson, 1999). 


\section{Bringing it all Together: A Theoretical Model of Student Leadership Development}

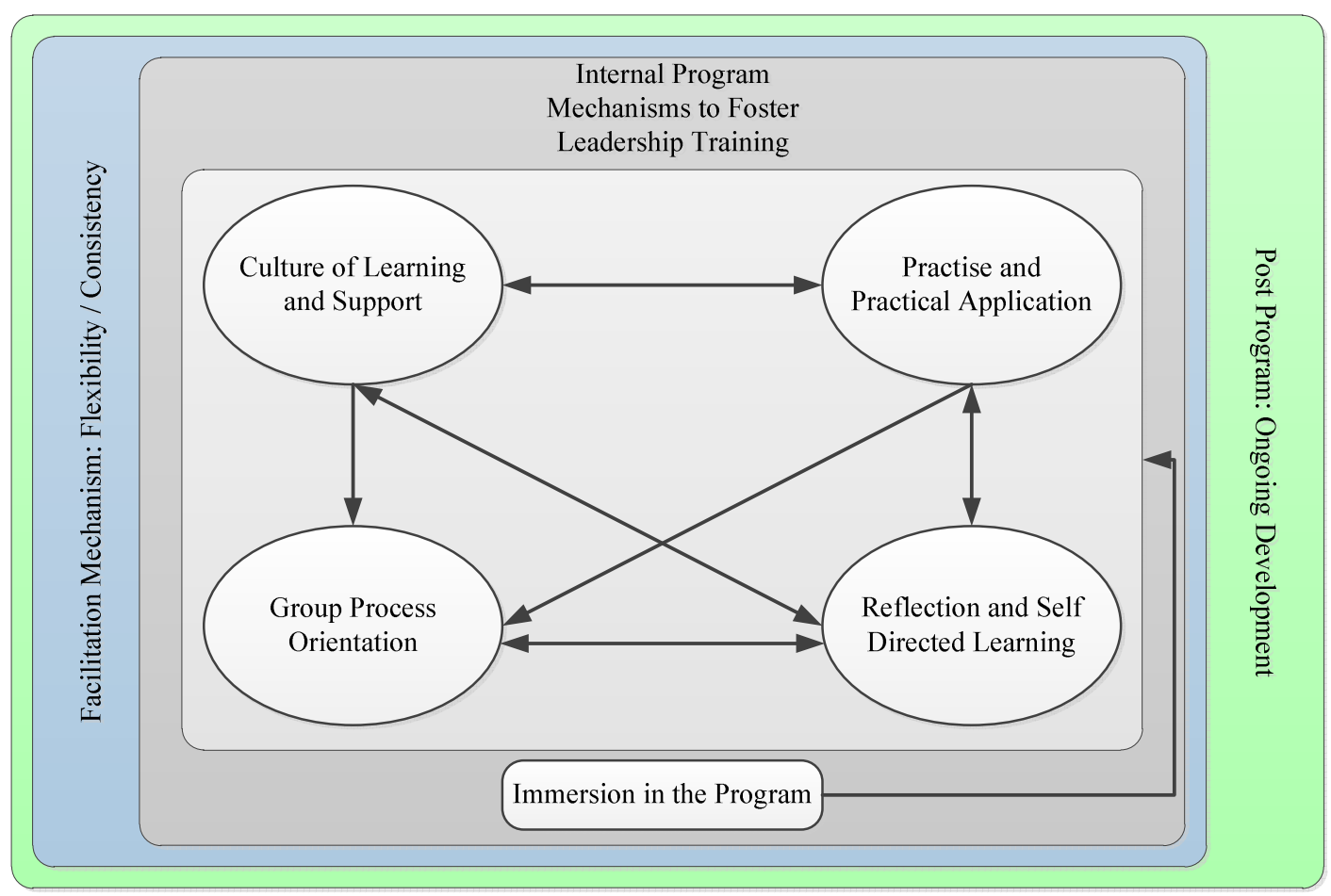

Figure 1.

As illustrated in Figure 1, the Theoretical Model of Student Leadership Development (above), there are several interrelationships among the identified themes, many of which work together or build upon one another to realize programmatic goals, necessitating the realization of each theme. As internal program mechanisms, themes one, two, three, and five are realized directly through the multipurpose exercises and initiatives facilitated throughout the training program. Concurrently, the theme of immersion influences the developmental goals and interrelations of each of these themes as they unfold. Acting as a facilitation mechanism outside of said relations, theme six is realized through the intervening actions of facilitators throughout the training, while theme seven, ongoing development, occurs after the program has concluded.

\section{Areas of Concern for Application of the Theoretical Model}

The seven themes were derived from the study of a highly successful student leadership program for the purpose of advancing our understanding of the characteristics of effective programs. However, there are some areas of concern that one may consider when applying this construct to a similar curriculum. For example, it was noted that participants were strongly in favour of continuing the 'retreat' style of living arrangements throughout the training program's second week to further develop trust and cohesiveness within the participant group.

Furthermore, as the program seeks to empower and build confidence within developing student leaders, including those participants who are returning to the training program, said 
returners are relied upon to fulfill a mentorship role while engaged in furthering their own development. As reasoned by Komives and colleagues (2006), experienced leaders are necessary for role modelling and support within more intense exercises. As a respondent explained, however, some returning participants require direction to work effectively in this regard:

"[Facilitators should] teach returners how to properly give feedback. There are times where...you see the [first-time participant distressed], believing they have done a terrible job, and returners giving them feedback of 'you did a good job.' No, they didn't do a good job, in fact, they did a [poor] job, you just don't want to tell them because you don't know how to give feedback and you're worried about hurting their feelings..."

In light of behaviours such as the example provided, it would be beneficial, then, to provide guidance to experienced participants so that they can be relied upon to be effective in their role, a role which, as the literature confirms, is necessary to provide legitimacy to the content within the training program (Komives et al., 2006).

Related to the theme of self-directed, reflection-based learning, it is important to understand the risks involved in presenting training initiatives wherein the desired outcomes differ significantly from the presented content, or are seemingly removed from what is perceived to be the purpose of the exercises in the eyes of participants. As referenced by respondents earlier in this writing, the emphasis the sample program places upon reflection and self-directed learning in many of its exercises is necessary to achieve the intended results; participants may not bond as a group - a common objective within many of the training exercises - just because they are made aware of this intention. However, as a respondent discussed, the success of said exercises hinges upon rather precise communication and content delivery:

"[The] effectiveness [of such exercises] depends hugely...on the exact words that are used... [if] there's a difference between the words that are used and the words that are intended... [if] they don't say a particular line or lay down a particular expectation...if that information does not get across, then those [exercises] are much less effective."

Respondents also noted that given the average age of the participant group, those in training need to believe that what they were learning is purposeful and suitable to the university culture (Ruben, 2005). As such, creating trust in the program within the participant group is vital to ensure participants are engaging in the exercises and absorbing training content (Eich, 2008).

Lastly, additional areas of concern addressed by respondents included: (1) ensure training exercises are varied in their design to accommodate various learning styles; (2) schedule the training program in such a way that support, trust, and connectedness amongst the group, in concert with basic skill development, is established through initial exercises before more intense material is presented; and (3) maintain open communication with participants leading up to the training program so they can mentally prepare for the intensity of the curriculum. 


\section{Summary of Program Examination}

Through the analysis of the sample training program, it is evident that the curriculum has been designed with strong end-goals in mind (to develop confident, self-aware student leaders who can function both independently and as part of a team) while maintaining a processual awareness of how to realize these goals (through developing a supportive culture and nurturing participant reflection). In applying the theoretical model, then, one must be equally mindful of the importance of the interrelations between the identified themes, considering each as a step towards realizing one's training and development objectives.

Additionally, it was found that empowering student leaders, training them to become effective communicators who can work effectively, both individually and as a part of a group, was far more useful in developing leadership qualities within students than exercises with a narrow focus specific to their current role. As summarized by a respondent,

"There are obviously [role]-specific things that you have to train... but [it is more important to] train [participants] on skills that they can use forever...those kind of things that they can transfer into any realm... [are] what's going to benefit them now, and later."

Lastly, through creating a supportive culture within the training program, the sample organization was able to incite a strong investment in the training content, which, ultimately, resulted in the development of effective student leaders.

\section{Implications and Contributions}

This study was conducted based on the belief that through the examination of an exemplary student leadership development program, a complete understanding of how leadership is fostered within students would be identified, which would, in turn, allow one to discern through what means similar results could be achieved. Through the analysis of the studied program, seven themes of student leadership development were identified, which illustrate the interrelated objectives one must balance to achieve programmatic success.

As summarized in Table 3, the findings of this study also serve as confirmation of past research in this area, as similarities to the findings of Eich (2008) were found within three of the identified themes. Accordingly, these findings serve to complement and extend the findings in the literature to present a more complete understanding of the necessary components of effective student leadership programs. 
Table 3

The identified themes in relation to existing literature

\begin{tabular}{lcc}
\hline $\begin{array}{c}\text { Eich's (2008) Attributes of high- } \\
\text { quality leadership } \\
\text { programs: }\end{array}$ & $\begin{array}{c}\text { Identified themes which } \\
\text { complement or } \\
\text { expand upon } \\
\text { existing } \\
\text { literature: }\end{array}$ & Newly identified themes: \\
\hline $\begin{array}{l}\text { 1. Participant engagement in } \\
\text { building and maintaining a } \\
\text { learning community }\end{array}$ & $\begin{array}{l}\text { A culture of learning } \\
\text { and support }\end{array}$ & $\circ \begin{array}{l}\text { Group process } \\
\text { orientation }\end{array}$ \\
$\begin{array}{l}\text { 2. Student-centered, experiential } \\
\text { learning }\end{array}$ & $\begin{array}{l}\text { The importance of } \\
\text { feedback and } \\
\text { practical application }\end{array}$ & $\begin{array}{l}\text { Ongoing development of } \\
\text { participants }\end{array}$ \\
$\begin{array}{l}\text { Flexible, grounded program } \\
\text { development }\end{array}$ & $\begin{array}{l}\text { Flexibility vs. } \\
\text { Consistency }\end{array}$ & $\begin{array}{l}\text { Immersion in the } \\
\text { program }\end{array}$ \\
\hline
\end{tabular}

In understanding these findings, in concert with existing literature, one may apply this information to a specific context, creating exercises to suit the specific needs and goals of a given program in line with the vital processual goals inherent within the seven identified themes.

\section{Conclusion}

This research sought to establish the importance of leadership within the undergraduate/student context, while providing an overall understanding of what constitutes an effective student leadership development program. Through the analysis of an exemplary program, a theoretical model and its components have been presented to conceptualize this understanding and present a template to aid the design of future programs. It is the hope of this author that institutions of higher education continue to focus on developing leadership within students, as, when effective, such training programs can have significant and lasting effects on students, positioning them for success now and in the future.

\section{References}

Abudi, Gina, "The Five Stages of Project Team Development," The Project Management Hut. Retrieved April 15, 2013, from http://www.pmhut.com/the-five-stages-of-project-teamdevelopment

Amagoh, Francis, "Leadership Development and Leadership Effectiveness," Management Decision, Vol. 47 No. 6, 2009, pp. 989-999. 
Allen, Scott J., \& Hartman, Nathan S., "Sources of Learning in Student Leadership Development Programming," Journal of Leadership Studies, Vol 3. No. 3, 2009, pp. 6-16.

Astin, Alexander W., Astin, Helen S., Allen, Kathleen E., Burkhardt, John C., Cress, Christine M., Flores, Robert A., Jones, Phillip., Lucas, Nance J., Pribush, Bonnie L., Reckmeyer, William C., Parker Smith, Bettye., Zimmerman-Oster, Kathleen A., "Leadership Reconsidered: Engaging Higher Education in Social Change," W.K. Kellogg Foundation, p. 1-103.

Boeije, Hennie, "A Purposeful Approach to the Constant Comparative Method in the Analysis of Qualitative Interviews," Quality \& Quantity, 36, 2002, pp. 391-409.

Boerner, Sabine, Eisenbeiss, Silke Astrid., Griesser, Daniel. "Follower Behaviour and Organizational Performance: The Impact of Transformational Leaders," Journal of Leadership and Organizational Studies, Vol. 13, No. 3, 2007, pp. 15-26.

Buckner, Kirk J. \& Williams, Lee M., "Applying the Competing Values Model of Leadership: Reconceptualising a University Student Leadership Development Program," The Journal of Leadership Studies, Vol. 2, No. 4, 1995, pp. 19-34.

Chickering, Arthur W. \& Gamson, Zelda F., "Development and Adaptations of the Seven Principles for Good Practice in Undergraduate Education," New Directions for Teaching and Learning, No. 80, Winter 1999, pp. 75-81.

Eich, Darin, "A Grounded Theory of High-Quality Leadership Programs," Journal of Leadership and Organizational Studies, Vol. 15, No. 2, November 2008, pp. 176-187.

Glaser, Barney G., Strauss, Anselm, L., "The Discovery of Grounded Theory: Strategies for Qualitative Research," Aldine Publishing Company, Chicago, 1967, p.1-113.

Howell, Jane M. \& Avolio, Bruce J., “Transformational Leadership, Transactional Leadership, Locus of Control, and Support for Innovation: Key Predictors of Consolidated-BusinessUnit Performance," Journal of Applied Psychology, Vol. 78, No. 6, 1993, pp. 891-902.

Judge, Timothy A. \& Piccolo, Ronald F., "Transformational and Transactional Leadership: A Meta-Analytic Test of Their Relative Validity," Journal of Applied Psychology, Vol. 89, No. 5, 2004, pp. 755-768.

Komives, Susan R., Longerbeam, Susan D., Owen, Julie E., Mainella, Felicia C., Osteen, Laura., "A Leadership Identity Development Model: Applications from a Grounded Theory," Journal of College Student Development, Vol. 47, No. 4, July/August 2006, pp. 401-418.

McCracken, G., “The Long Interview,” SAGE Publications, Inc, 1988, p. 1-50

Osiemo, Lynette B., "Developing Responsible Leaders: The University at the Service of the Person," Journal of Business Ethics, 108, 2012, pp. 131-143. 
Piccolo, Ronald F., Bono, Joyce E., Heinitz, Kathrin., Rowold, Jens., Duehr, Emily., Judge, Timothy A., "The Relative Impact of Complementary Leader Behaviours: Which Matter Most?" The Leadership Quarterly, 23, January 2012, pp. 567-581.

Piccolo, Ronald F., \& Colquitt, Jason A., "Transformational Leadership and Job Behaviours: The Mediating Role of Core Job Characteristics," Academy of Management Journal, Vol. 49, No. 2, 2006, pp. 327-340.

Ruben, Brent D., "The Center for Organizational Development and Leadership at Rutgers University: A Cast Study," Advances in Developing Human Resources, Vol. 7, No. 3, August 2005, pp. 368-395.

Strauss, Anselm, Corbin, Juliet. “Grounded Theory Methodology: An Overview," Strategies of Inquiry, 1994, pp. 273-285.

Suri, Harsh. "Purposeful Sampling in Qualitative Research Synthesis," Qualitative Research Journal, Vol. 11, No. 2, 2011, pp. 63-75.

Welbourne, Theresa M., Cavanaugh, Marcie A., Judge, Timothy A., "Does the Leader Make a Difference? Relationship Between Executive Leader Personality and Entrepreneurial Firm Performance," CAHRS Working Paper \#98-17, Cornell University, School of Industrial and Labor Relations, September 1998, p. 1-22.

Yukl, Gary. "Leadership in Organizations," National College for School Leadership, 2003, p. 14.

Zenger, Jack. "We Wait Too Long to Train Our Leaders," Harvard Business Review. Retrieved December 19, 2012, from http://blogs.hbr.org/cs/2012/12/why_do_we_wait_so_long_to_trai.html

Zimmerman-Oster, Kathleen, Burkhardt, John C., "Leadership in the Making: A Comprehensive Examination of the Impact of Leadership Development Programs on Students," The Journal of Leadership Studies, Vol. 6, No. 3/4, 1999, pp. 51-66.

\section{Author Biography}

Stewart G. Grunwell is a recent graduate of the MBA program at the Goodman School of Business, Brock University. In September 2014, he joined the PhD program at the DeGroote School of Business, McMaster University, where he is currently pursuing his doctorate in Human Resources and Management. His current research interests include student leadership, emotion regulation, and dramaturgical analysis within organizational contexts. 